\title{
Resistance to Alternaria solani in Hybrids Between a Solanum tuberosum Haploid and S. raphanifolium
}

\author{
B. N. Weber and S. H. Jansky
}

First and second authors: Department of Horticulture, University of Wisconsin, Madison 53706; and second author: United States Department of Agriculture-Agricultural Research Service. Accepted for publication 7 October 2011.

\section{ABSTRACT}

Weber, B. N., and Jansky, S. H. 2012. Resistance to Alternaria solani in hybrids between a Solanum tuberosum haploid and S. raphanifolium. Phytopathology 102:214-221.

Early blight of potato (Solanum tuberosum), caused by the foliar fungal pathogen Alternaria solani, is a major cause of economic loss in many potato-growing regions. Genetic resistance offers an opportunity to decrease fungicide usage while maintaining yield and quality. In this study, an early blight resistant clone of the diploid wild species $S$. raphanifolium was crossed as a male to a haploid $(2 \mathrm{n}=2 \mathrm{x})$ of cultivated potato. Hybrids were backcrossed to both parents. Eight families were created and evaluated for early blight resistance in the field. Families created by backcrossing to the wild species parent exhibited significantly lower relative area under the disease progress curve means than those from backcrossing to the cultivated parent, leading to the conclusion that $S$. raphanifolium contributes genes for early blight resistance. The mechanism of resistance in $S$. raphanifolium is unique because A. solani could not be recovered from lesions. Clones were identified with high levels of resistance and adaptation to the photoperiod of a temperate production region.
Early blight (EB) of potato (Solanum tuberosum L.), caused by the foliar fungal pathogen Alternaria solani Sorauer, is a major cause of economic losses in many potato-growing regions $(7,19)$. A. solani reproduces asexually via multicellular conidia, with no sexual cycle presently known $(1,19)$. A solani is polycyclic because it infects plants many times throughout the growing season; the fungus overwinters as mycelia or conidia in the soil or plant debris $(1,14)$. Symptoms associated with EB are small, irregular, dark lesions that range in size and, as they enlarge, form concentric rings and give a characteristic "target-spot" effect $(1,5)$. Older senescing leaves are typically more susceptible to EB than younger leaves and require a shorter incubation period for infection to occur $(8,16,17)$. Consequently, early-maturing cultivars are more susceptible to EB than medium- or late-maturing cultivars because leaves of early-maturing cultivars tend to senesce earlier in the growing season (9). The incidence and severity of EB infections tend to increase with exposure to overhead irrigation or extended periods of leaf wetness (19).

EB is a difficult fungal disease to control. Cultural practices, such as rotations with non-host crops, field sanitation, and planting disease-free seed, are implemented to reduce disease but fungicide applications every 7 to 10 days are still required. Although all major potato cultivars are susceptible to $\mathrm{EB}$, potato breeders have not placed a high priority on EB resistance due to a long history of readily available, low-cost, and highly effective foliar fungicides. With increasing costs for disease control, as well as social and environmental concerns surrounding fungicide use, there is a growing interest in the development of potato cultivars with resistance to EB.

Corresponding author: S. H. Jansky; E-mail address: Shelley.jansky@ ars.usda.gov

* The $\boldsymbol{e}$-Xtra logo stands for "electronic extra" and indicates that the online version conatins a supplemental table. Figure 6 appears in color online.

http://dx.doi.org/10.1094/PHYTO-05-11-0146

This article is in the public domain and not copyrightable. It may be freely reprinted with customary crediting of the source. The American Phytopathological Society, 2012.
Wild potato relatives may provide an alternative method of EB control. The diploid wild potato relative $S$. raphanifolium Cardenas and Hawkes (rap) is a low-growing, semi-rosette plant found at altitudes of 2,800 to $3,800 \mathrm{~m}$ in southern Peru in cultivated regions, volcanic soil, and open rocky or grassy regions (10) and has been reported to possess high levels of EB resistance (13). This EB resistance can be incorporated into cultivated potato through crosses to haploids $(2 \mathrm{n}=2 \mathrm{x})$ derived from tetraploid cultivars. One clone from $S$. raphanifolium plant introduction (PI) 473369 (119-2) was examined in this experiment. The objective of this study was to evaluate EB resistance in hybrid and backcross families derived from crossing rap 119-2 as a male to USW4, a haploid clone derived from an S. tuberosum advanced selection.

\section{MATERIALS AND METHODS}

Plant material. Haploid-wild species hybrids were created by crossing US-W4, a haploid cultivated $(2 \mathrm{n}=2 \mathrm{x}=24) S$. tuberosum clone as a female to $S$. raphanifolium (rap 119-2), a wild $(2 \mathrm{n}=2 \mathrm{x}=24)$ species clone. US-W4 was generated via parthenogenesis from the Minnesota advanced selection MN 20-20-34 in 1956 as a result of a joint collaboration among the University of Wisconsin, the United States Department of Agriculture-Agricultural Research Service, and the IR-1 Potato Gene Bank and has been maintained clonally since then (15). The accession from which rap 119-2 was derived (PI 473369) was collected in Cuzco, Peru in 1971 under bushes on a rocky slope, and is now maintained by the NRSP-6 Potato Gene Bank in Sturgeon Bay, WI.

Five hybrid clones $(\mathrm{H} 1, \mathrm{H} 2, \mathrm{H} 3, \mathrm{H} 4$, and $\mathrm{H} 5)$ were randomly selected from a population of US-W4 $\times$ rap 119-2 hybrids and then backcrossed to both US-W4 and rap 119-2. Five families were produced by backcrossing the five hybrids as females to the wild parent rap 119-2; their designations are H1W (hybrid clone $\mathrm{H} 1 \times$ wild parent), $\mathrm{H} 2 \mathrm{~W}, \mathrm{H} 3 \mathrm{~W}, \mathrm{H} 4 \mathrm{~W}$, and $\mathrm{H} 5 \mathrm{~W}$. Two families were generated from backcrosses between two of the hybrids as females and the cultivated parent, US-W4; they are designated 
$\mathrm{H} 2 \mathrm{C}$ (hybrid clone $\mathrm{H} 2 \times$ cultivated parent) and $\mathrm{H} 3 \mathrm{C}$. Attempts to backcross the other three hybrids to US-W4 were unsuccessful due to unidentified hybridization barriers. The cultivated US-W4 $\times$ wild species rap 119-2 (CW) hybrid family was also included in the study. The five hybrid clones were also used to pollinate both rap 119-2 and US-W4 but seed were not produced due to a stylar incompatibility barrier.

Field studies. The eight families were examined in the field during the 2008 and 2009 growing seasons, using seed generated in a greenhouse between 2007 and 2009. In April, seed were soaked in 1,500 ppm gibberellic acid (Sigma-Aldrich, St. Louis) for $24 \mathrm{~h}$ and then sown in a peat-based potting mix. Individual seedlings were transplanted to separate pots in early May. Seedlings were then transplanted into field plots at the Hancock Agricultural Experiment Station, Hancock, WI on 4 June 2008 and 2009. The soil is a Plainfield loamy sand (92\% sand, 5\% silt, 3\% clay, and $<1 \%$ organic matter). The plots were surrounded by potato fields grown for commercial and research purposes. Standard cultural practices were used, except that fungicides were not applied (Supplemental Table 1). Insecticides were applied every 7 to 10 days throughout both growing seasons to control Colorado potato beetles (Leptinotarsa decemlineata Say). Temperature and precipitation data were collected during both growing seasons.

The experimental design was a randomized complete block with two replications. Half of the seedlings in each family were planted in one replication and the other half were placed in the second replication. Consequently, the genotypes in the first replication were not identical to those in the second replication. Each block consisted of transplants spaced $61 \mathrm{~cm}$ apart and parents or checks spaced $30.5 \mathrm{~cm}$ apart. In 2008, two replications of 54 seedlings of each of the eight families and three clonal replications (four tuber seed pieces per rep) of the parents and checks were planted. In 2009, when more seed was available, two replications of either 54 seedlings (families $\mathrm{CW}, \mathrm{H} 1 \mathrm{~W}, \mathrm{H} 4 \mathrm{~W}$, and $\mathrm{H} 5 \mathrm{~W}$ ) or 100 seedlings (families H2C, H3C, H2W, and H3W) for each of the eight families and four clonal replications of the parents and check varieties were planted. The survival rate of transplants in 2008 was lower than projected due to an unexpected Colorado potato beetle ( $L$. decemlineata) infestation shortly after transplanting; therefore, seedling numbers were increased from 54 to 100 for reciprocal backcrosses (hybrid clones backcrossed to both parents) families in 2009. 'Atlantic' and 'Russet Burbank' were utilized as susceptible checks and 'C75$5+297$ ', developed from a somatic hybrid of S. tuberosum $+S$. brevidens (18), served as a resistant check in both years. In 2009, Russet Burbank was additionally planted at the end of each family throughout the field to aid in even spread of natural inoculum.

A. solani was allowed to naturally infest the field plots via wind-blown inoculum in both years. To ensure that symptoms observed were due to the infection of $A$. solani, a random sampling of leaves exhibiting EB lesions was collected from plants with varying breeding backgrounds across years. Three 3- to 4-mm ${ }^{2}$ tissue samples were excised from the margins of EB lesions and placed on clarified V-8 (CV8) medium (100 ml of clarified V8 juice, $1.5 \mathrm{~g}$ of $\mathrm{CaCO}_{3}, 900 \mathrm{ml}$ of $\mathrm{dH}_{2} \mathrm{O}$, and $12.7 \mathrm{~g}$ of agar) amended with streptomycin $(25 \mu \mathrm{g} / \mathrm{ml})$ and kanamycin $(50 \mu \mathrm{g} / \mathrm{ml})$. Plates were incubated at room temperature in ambient light for 24 to $48 \mathrm{~h}$ to induce hyphal growth, and then transferred to $20^{\circ} \mathrm{C}$ under continuous light for 3 to 4 days to induce sporulation. Cultures were then examined for A. solani spores.

To evaluate EB progression, individual plants were assigned an EB severity percentage score from mid-August to mid-September across four scoring dates: 77, 85, 90, and 100 days after planting (dap) in 2008 and 76, 83, 88, and 100 dap in 2009 using the Horsfall-Barratt scale (0-to- 11 scale where $0=$ no disease and $1=$ 1 to $3 \%$ or few lesions, $2=4$ to $6 \%$ or few leaflets dying, $3=7$ to $12 \%$ or leaflets dying and branches starting to die-back, $4=13$ to
$24 \%$ or up to one-fourth foliage dead, $5=25$ to $50 \%$ or onefourth to one-half foliage dead, $6=51$ to $75 \%$ or one-half to three-quarter foliage dead, $7=76$ to $88 \%$ or three-quarters foliage dead, $8=89$ to $94 \%$ or few leaves alive, $9=95$ to $97 \%$ or 1 to 5 leaflets alive, $10=98$ to $99 \%$ or only green stems, and $11=100 \%$ of plant foliage is exhibiting symptoms) (11). Percent defoliation and the average fraction of necrotic leaf area on the plant were examined using this scale. Assigned scores for each plant collected across the four scoring dates in a single growing season were then used to calculate area under the disease progress curve (AUDPC) per plant. AUDPC was calculated using the formula (4) AUDPC $=\sum_{i=1}^{n-1}\left[\left(t_{i+1}-t_{i}\right)\left(y_{i}+y_{i+1}\right) / 2\right]$, in which $t_{i}=$ time of each reading (days after planting), $y_{i}=$ percentage of affected foliage at each rating and $n=$ number of readings. AUDPC was then used to calculate a relative AUDPC (RAUDPC) value per plant. RAUDPC measures the relative severity of disease throughout the growing season, with a value of 1.0 equivalent to $100 \%$ foliage infection (18). It is calculated by dividing AUDPC scores by the largest possible AUDPC score across the scoring season.

Statistical analysis. An analysis of variance (ANOVA) was performed using PROC MIXED in SAS (version 9.2; SAS Institute Inc., Cary, NC) on family mean RAUDPC values. Models were fit for data combined over years and separately for each year. In the combined-year model, family, year, and the familyyear interaction were considered to be fixed effects. Models fit to individual years contained only family as a fixed effect. Replication was included as a random effect in all models. Based on the PROC MIXED results, RAUDPC family means were compared using the Tukey multiple comparison correction.

All graphs were made in either Microsoft Excel (2007) or R 2. 8.1 (2008). Equal variance and normality assumptions were checked and found to be met for all PROC MIXED analyses. For all statistical tests, significance was inferred at $P=0.05$.

\section{RESULTS}

RAUDPC trends among families. Significant differences among mean family RAUDPC values $(P<0.0001)$ were revealed in 2008 and 2009 (Table 1). Years were examined separately due to highly significant year and family-year interaction effects $(P<$ 0.0001). The male parent (US-W4 or rap 119-2) used in backcrosses affected overall family performance. Based on the RAUDPC least square means in 2008, families $\mathrm{H} 2 \mathrm{C}(0.57)$ and H3C (0.67) (hybrid clones backcrossed to cultivated US-W4) had the highest mean values (most susceptible to $\mathrm{EB}$ ) and were significantly different from four of the five families (values of 0.27 to 0.37 ) created by backcrossing hybrids to rap 119-2 (the exception was family $\mathrm{H} 5 \mathrm{~W}$ at 0.50 ) (Table 2). In 2009, family CW (cultivated haploid US-W4 $\times$ wild rap 119-2) had the thirdhighest full-season RAUDPC mean of 0.43 and was also significantly more susceptible than most families created by backcrossing hybrid clones to rap 119-2. Family least square RAUDPC means varied somewhat between 2008 and 2009, causing a rank shift. Nevertheless, families $\mathrm{CW}, \mathrm{H} 2 \mathrm{C}$, and $\mathrm{H} 3 \mathrm{C}$ still had high

TABLE 1. Analysis of variance of individual and combined year relative area under disease progress curve values ${ }^{\mathrm{y}}$

\begin{tabular}{llrcc}
\hline Year $^{\mathrm{z}}$ & \multicolumn{1}{c}{ Source } & DF & $F$ value & $P>F$ \\
\hline 2008 & Family & 7 & 27.6 & $<0.0001$ \\
& Error & 400 & $\ldots$ & $\ldots$ \\
\multirow{2}{*}{ Combined } & Family & 7 & 14.52 & $<0.0001$ \\
& Error & 636 & $\ldots$ & $\ldots$ \\
& Yearily & 7 & 37.58 & $<0.0001$ \\
\multirow{2}{*}{ Error } & Family $\times$ year & 1 & 28.59 & $<0.0001$ \\
& $\ldots$ & 7 & 11.15 & $<0.0001$ \\
\hline
\end{tabular}

y Data were obtained from a PROC MIXED analysis in SAS.

${ }^{\mathrm{z}}$ Combined $=$ combined years 
RAUDPC mean values and, for the most part, were more susceptible than families created by backcrossing to rap 119-2 in 2008 and 2009.

To visualize the distribution of RAUDPC means within and among families, box plots were created (Fig. 1). A high level of variation was observed within and among family RAUDPC scores. Families created by backcrossing hybrid clones to rap 119-2 (medium gray color in figure) exhibited a lower median RAUDPC value in 2008 (0.29 to 0.47) and 2009 (0.28 to 0.35) than when hybrid clones were backcrossed to US-W4 (light gray) in 2008 (0.62 to 0.67 ) and 2009 (0.41 to 0.42). Individual clones in family CW (black) were found to have larger distributions of RAUDPC values in 2008 than families created by backcrossing to either the resistant (rap 119-2) or susceptible parent (US-W4). In contrast, most families in 2009 exhibited a broad distribution of scores. However, as in 2008, families created by backcrossing to rap 119-2 exhibited lower median RAUDPC values than backcrosses to US-W4, and segregation was observed in family CW (Fig. 2).

RAUDPC trends among parents. The range of RAUDPC values was smaller among clonal propagules of parents (Fig. 3) than among individuals within families (Fig. 1). RAUDPC median values for parents were high or low depending on whether they were susceptible or resistant, respectively. Haploid US-W4 and hybrid clones $\mathrm{H} 2$ and $\mathrm{H} 3$ exhibited higher median scores, indicative of susceptibility to A. solani, whereas wild rap 119-2 and hybrid clones $\mathrm{H} 4$ and $\mathrm{H} 5$ exhibited lower median scores, indicating resistance to A. solani. Hybrid $\mathrm{H} 1$ was not evaluated in the field due to a lack of seed availability. Interestingly, the resistant parent rap 119-2 had a low median value but a large distribution of RAUDPC values compared with other resistant parents even though all individuals were clones and, therefore, genetically identical. This indicates that resistance scores were likely confounded by unknown factors in the field.

Interactions. Genotype-environment interactions were observed across the 2 years of the study. Mean EB scores of all families spanning all score dates in 2008 were significantly higher $(P<$ 0.0001) than in 2009 (Fig. 4). Similarly, resistant and susceptible check mean EB scores were also significantly higher in 2008 than 2009 (data not shown). Precipitation and temperature were examined in an attempt to explain the change in disease pressure

TABLE 2. Relative area under the disease progress curve means comparisons of haploid-wild species hybrid families in 2008 and $2009^{y}$

\begin{tabular}{llc}
\hline Family $^{z}$ & Mean & Standard error $( \pm)$ \\
\hline 2008 & & \\
H3C & $0.67 \mathrm{~A}$ & 0.043 \\
CW & $0.58 \mathrm{AB}$ & 0.022 \\
H2C & $0.57 \mathrm{ABC}$ & 0.039 \\
H5W & $0.50 \mathrm{BC}$ & 0.029 \\
H4W & $0.37 \mathrm{D}$ & 0.025 \\
H3W & $0.37 \mathrm{DE}$ & 0.030 \\
H2W & $0.34 \mathrm{DE}$ & 0.029 \\
H1W & $0.27 \mathrm{E}$ & 0.026 \\
2009 & & \\
H2C & $0.51 \mathrm{~A}$ & 0.017 \\
H3C & $0.48 \mathrm{AB}$ & 0.017 \\
CW & $0.43 \mathrm{BC}$ & 0.014 \\
H5W & $0.39 \mathrm{CD}$ & 0.015 \\
H2W & $0.35 \mathrm{D}$ & 0.019 \\
H4W & $0.35 \mathrm{D}$ & 0.018 \\
H1W & $0.32 \mathrm{D}$ & 0.026 \\
H3W & $0.31 \mathrm{D}$ & 0.021 \\
\hline
\end{tabular}

${ }^{\mathrm{y}}$ Means in a column with the same letter are not significantly different at $P=$ 0.05 using the Tukey multiple comparison procedure. Families are arranged from least to most resistant.

${ }^{\mathrm{z}}$ Family abbreviations are written as female parent followed by male parent. Female parent abbreviations: cultivated US-W4 (C) and cultivated US-W4 $\times$ wild $S$. raphanifolium hybrids (H1-H5). Male parent abbreviations: cultivated US-W4 (C) and wild S. raphanifolium (W). between years. Monthly precipitation (both rain and irrigation) in June $(170.4 \mathrm{~mm})$, July $(115.3 \mathrm{~mm})$, and August $(61.0 \mathrm{~mm}) 2008$ was significantly higher than in June $(68.8 \mathrm{~mm})$, July $(55.4 \mathrm{~mm})$, and August (82.6 mm) 2009. Monthly average temperatures in June $\left(17.9^{\circ} \mathrm{C}\right)$, July $\left(21.1^{\circ} \mathrm{C}\right)$, and August $\left(20.1^{\circ} \mathrm{C}\right) 2008$ compared with June $\left(18.4^{\circ} \mathrm{C}\right)$, July $\left(18.8^{\circ} \mathrm{C}\right)$, and August $\left(17.8^{\circ} \mathrm{C}\right)$ 2009 were found to vary by year. In addition, A. solani cultures obtained from leaves in the 2008 and 2009 trials were analyzed to determine whether isolate variability might explain differences in disease severity between years.

Reciprocal backcrosses. Four haploid-wild species hybrid families ( $\mathrm{H} 2 \mathrm{~W}, \mathrm{H} 2 \mathrm{C}, \mathrm{H} 3 \mathrm{~W}$, and $\mathrm{H} 3 \mathrm{C})$ were selected for additional analysis because they represented backcrosses to both parents. In both years, RAUDPC scores in families $\mathrm{H} 2 \mathrm{~W}$ and $\mathrm{H} 3 \mathrm{~W}$, which were created by backcrossing hybrid clones $\mathrm{H} 2$ and H3 to the resistant wild parent (rap 119-2), displayed lower RAUDPC values than families $\mathrm{H} 2 \mathrm{C}$ and $\mathrm{H} 3 \mathrm{C}$, which were created
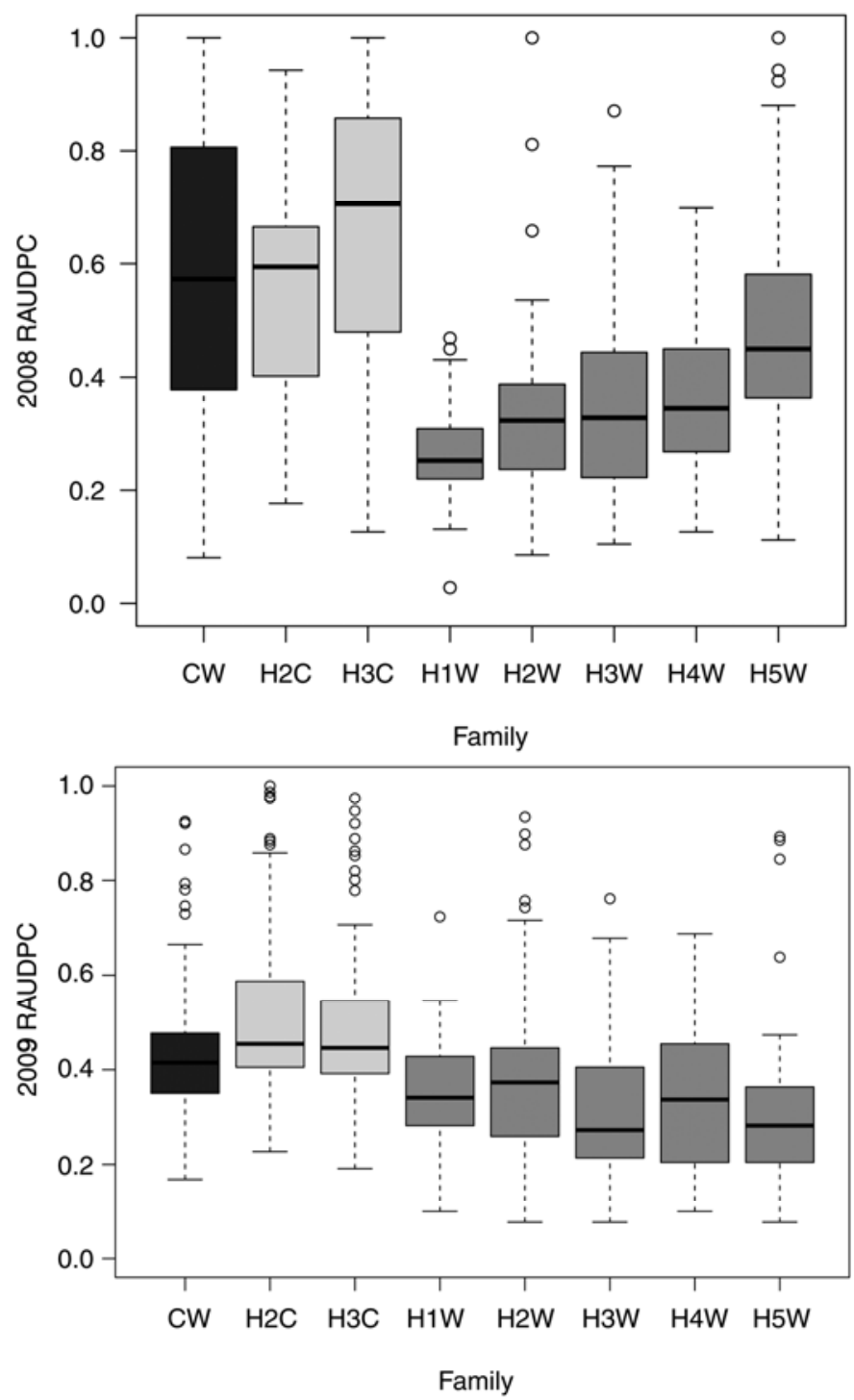

Fig. 1. Box plots showing relative area under the disease progress curve (RAUDPC) score distribution of haploid-wild hybrid species families grown in 2008 (top) and 2009 (bottom). Each whisker represents 25\% of individual scores, while the box region contains $50 \%$ of individuals, with the middle line representing the median value. All circles above or below each box plot represent outliers. High scores indicate susceptibility. Family CW (black) is US-W4 $\times$ Solanum raphanifolium (rap 119-2) hybrid offspring. Susceptible families (H2C and $\mathrm{H} 3 \mathrm{C}$ ) (light gray) are hybrids backcrossed to US-W4, while resistant families ( $\mathrm{H} 1 \mathrm{~W}, \mathrm{H} 2 \mathrm{~W}, \mathrm{H} 3 \mathrm{~W}, \mathrm{H} 4 \mathrm{~W}$, and $\mathrm{H} 5 \mathrm{~W}$ ) (medium gray) are hybrids backcrossed to $S$. raphanifolium (rap 119-2). 
by backcrossing hybrid clones $\mathrm{H} 2$ and $\mathrm{H} 3$ to the susceptible cultivated parent (US-W4) (Fig. 5). Backcrosses to the resistant parent (rap 119-2) exhibited significantly lower RAUDPC means than backcrosses to the susceptible parent, leading to the conclusion that $S$. raphanifolium is contributing genes for EB resistance (Table 2).

\section{DISCUSSION}

These experiments demonstrated that the wild species $S$. raphanifolium (rap 119-2) exhibits a high level of EB resistance in the field. Because previous studies were based on laboratory assays (13), it is important to confirm that this source of resistance is effective in whole plants under natural field conditions. $S$. raphanifolium appears to possess a unique source of EB resistance because, although small lesions were observed on fieldgrown plants exposed to the pathogen, $A$. solani could not be isolated from those lesions. In contrast, $A$. solani was isolated from the wild species $S$. berthaultii (data not shown) that has also been identified as a source of EB resistance (13). The type of resistance observed in $S$. raphanifolium has not been previously reported in potato and is likely to be especially valuable for potato producers. If the pathogen cannot grow and reproduce on potato leaves, then not only will plants carrying this resistance factor be protected but also inoculum production will be dramatically reduced and adjacent fields will be subjected to less disease pressure, even if they contain susceptible plants. In addition, because breeders have a well-defined target for resistance breeding, it will be possible to separate true resistance from that based on late maturity.

In addition, this work is important in demonstrating that resistance from this wild species can be effectively transferred to the cultivated potato as a result of hybridization with $S$. tuberosum. The hypothesis that rap 119-2 makes a genetic contribution to EB resistance was supported by the observation of resistance in its offspring. There was a significant male parent (rap 119-2 and US-
W4) effect in 2008 and 2009, with offspring derived from rap 119-2 more resistant than those from US-W4 (Table 3). The effect of the female hybrid parent $(\mathrm{H} 2$ and $\mathrm{H} 3$ ) was not significant in 2008 but it was significant in 2009 . This may be due to decreased inoculum pressure in 2009, making it possible to distinguish among moderately resistant hybrid clones.

The cultivated haploid parent US-W4 does not exhibit EB resistance but it contributes desirable agronomic characteristics to offspring when crossed to wild species (12). Although not systematically evaluated in this trial, a sampling of EB-resistant clones in the field revealed variation for tuber size and number. A subsequent trial in the field in 2010 confirmed that selected clones retain their EB resistance and produce tubers of acceptable agronomic quality. Tuber samples of four clones examined in the 2010 field trial are shown in Figure 6. Results of the current study and another experiment by Jansky (12) indicate that US-W4 should be implemented into breeding programs due to its exceptional parental qualities.

Distributions of individual RAUDPC values were found to be largest in family CW in 2008; in 2009, family RAUDPC distributions were similar across all families. It was not surprising to observe variation among individuals in family $\mathrm{CW}$, because they are haploid-wild species hybrids created by crossing an EB-susceptible and -resistant parent. The cultivated haploid was derived by parthenogenesis from a tetrasomic tetraploid clone, whereas the wild species parent was self-compatible and collected from natural population; consequently, both parents are expected to be heterozygous at a large proportion of alleles.

Mean EB scores indicated that disease severity was higher in 2008 than in 2009 It is difficult to determine whether inoculum spreader plants in 2009 distributed inoculum more evenly throughout the field because disease severity was lower in that year. Precipitation and temperature were examined in an attempt to explain the change in disease pressure between years. In order to germinate, A. solani spores require a period of wetness, which

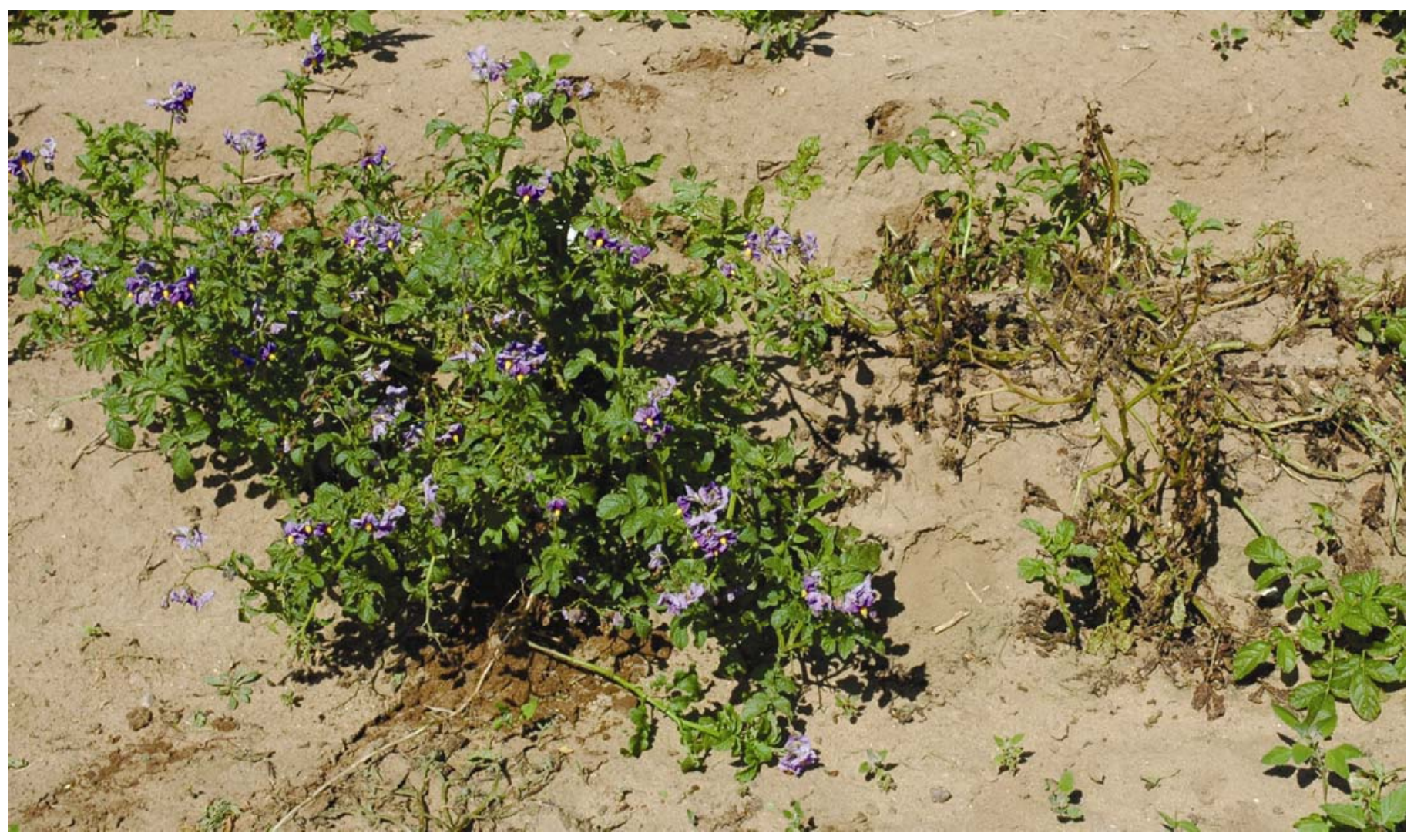

Fig. 2. Segregation for early blight symptoms in two clones of cultivated US-W4 $\times$ wild Solanum raphanifolium (rap 119-2) hybrid offspring. The resistant clone (left) exhibited few lesions, whereas the susceptible one (right) displayed numerous lesions that coalesced over time, leading to leaf death. 
can only be achieved by a heavy dew or rainfall (19). The heavy precipitation in June and July 2008 compared with 2009 may have accounted for the increased disease pressure in 2008. The ample rainfall provided during June and July 2008 would have allowed for frequent spore germination, resulting in a large inoculum population throughout the field and more opportunity for infections. Monthly average temperatures were similar in June across years, but July and August were warmer in 2008 than in 2009. The highest rate of $A$. solani sporulation occurs after a heavy rain or dew, at temperatures of 5 to $30^{\circ} \mathrm{C}$, with an optimal temperature of $20^{\circ} \mathrm{C}(3,16)$. Additionally, temperatures of 10 to $25^{\circ} \mathrm{C}$ are required for germ tube growth and penetration into leaves (5). Mean monthly temperatures in 2008 were closer to optimal than in 2009. Comparisons of $A$. solani isolates obtained from infected leaves of the parents and hybrids in the field trials in both years revealed that variation in virulence among isolates was low (20). Consequently, weather was likely a more important determinant of disease severity.
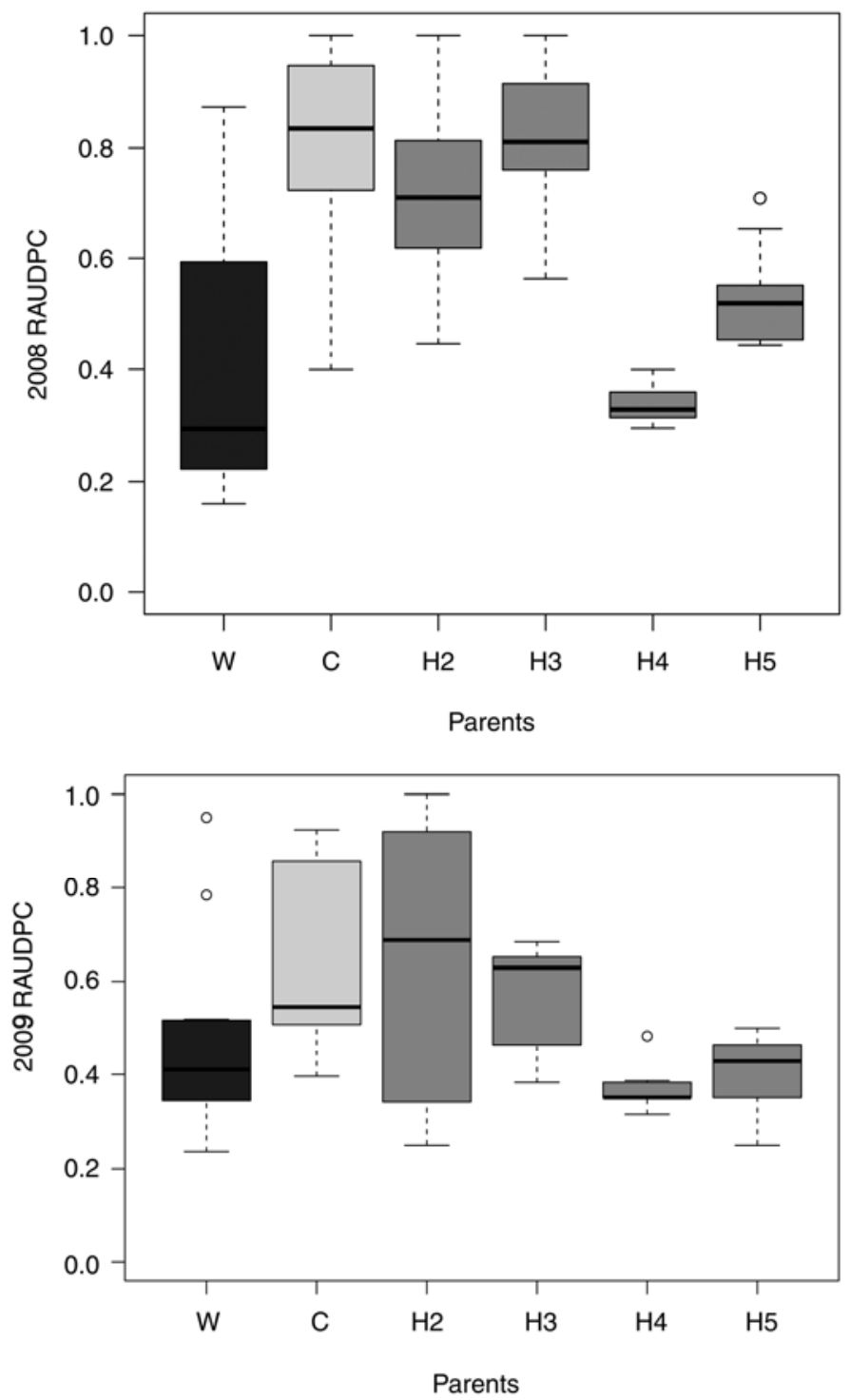

Fig. 3. Box plots showing relative area under the disease progress curve score distribution of parent clones grown in 2008 (top) and 2009 (bottom). Each whisker represents $25 \%$ of individual scores, while the box region contains $50 \%$ of individuals, with the middle line representing the median value. All circles above or below each box plot represent outliers. Larger relative area under disease progress curve (RAUDPC) scores indicate greater susceptibility. Solanum raphanifolium (rap 119-2) (W) is represented by dark gray shading, cultivated US-W4 (C) by light gray shading, and hybrids (H2, H3, H4, and $\mathrm{H} 5)$ by medium gray shading. Hybrid 1 (H1) is not present in graphs.
To visually assess differences in disease severity, family RAUDPC least squares means were calculated for 2008 and compared with the 2009 data. All families in 2009 exhibited a lower RAUDPC mean than in 2008, due to less disease pressure, as discussed above. In 2009, a large number of outliers resulted in a wide distribution of RAUDPC scores but the factor or factors that may have caused so many outliers is unknown. However, a large genotype-environment interaction was observed in 2009. In addition, rows in plots were oriented north to south in 2008 (perpendicular to prevailing winds) and east to west in 2009. This also may have contributed to the increased presence of outliers in 2009. Finally, plants also varied in growth form, from compact to sprawling, and plants were larger in 2009 than in 2008 (not shown). Morphologically variable plants likely create variable conditions for infection, due to changes in the microclimate (6). Leaf wetness and high relative humidity are important for the success of $A$. solani infection, because they are required for spore germination (19). Consequently, plant morphology may influence local disease pressure.

To account for differences among hybrid clones, RAUDPC values were assigned to each plant (clone). This allowed an assessment of EB progression across the season for every plant and was less time consuming than other methods of assessment such as counting lesions or measuring lesion size. Consequently, it was possible to evaluate a large number of plants. A midAugust to mid-September observation period was found to be especially useful for evaluating field material in this experiment for EB resistance (20). AUDPC can be biased if readings are taken too long after susceptible cultivars reach a high level of infection, leading to an underestimation of differences between resistant and susceptible clones (2). Two susceptible checks and one resistant check were included in both years. Atlantic and Russet Burbank were selected based on susceptible EB rating scores in previous studies (18). The resistant check, C75-5 +297, was selected based on the findings of Tek et al. (18). This study supports previous studies, in that C75-5+297 exhibited considerably more EB field resistance than Atlantic and Russet Burbank. In contrast, rap 119-2 clones exhibited more variability in symptom development than the other parent and check clones. This was surprising because, as a clone, rap 119-2 is not segregating for $\mathrm{EB}$ resistance. Factors other than $\mathrm{EB}$ pressure such as exposure to traditional potato production practices that were not optimized for wild potato species likely affected rap 119-2 scores. At each evaluation period, very few EB lesions were observed on the leaves of resistant clones and they did not increase in size or form concentric rings, as was observed on susceptible clones. However, a bronze discoloration spread across the plant foliage as the season progressed. An effort was made to evaluate the rap 119-2 plants for only EB symptoms but that became more difficult as the season progressed. Attempts were made to isolate organisms from regions of leaves exhibiting the bronze symptoms but no pathogenic source was determined. There is increasing interest among potato breeders in using wild Solanum spp. as sources of disease resistance. Although these species are valuable additions to breeding programs, as demonstrated by this study, it is important to note that unexpected phenotypes may be introduced through the use of exotic germplasm.

Although family sizes varied due to transplant death during the first two field weeks in 2008, they were still statistically large enough to meet PROC MIXED assumptions. Losses were due to an unexpected Colorado potato beetle ( $L$. decemlineata) infestation before the transplants had rooted deeply enough to take up systemic insecticides. In 2009, extra precautions were taken to avoid large losses of seedlings after transplanting. Seedlings were treated with a systemic insecticide before being taken to the field, and extra field scouting and foliar sprays were administrated as needed after transplanting. Additionally, larger populations were initially started in 2009 to compensate for potential high trans- 
plant mortality rates. In early July 2009, urea was applied as a part of standard potato cultural practices. It caused wilt and dieback on many transplants, especially those containing a high proportion of rap 119-2 germplasm. Plants exhibiting severe dieback were not evaluated. However, even with the elimination of those transplants, family sizes were still statistically large enough to meet model assumptions. Interestingly, this supports the hypothesis that rap 119-2 has an increased sensitivity to chemicals used in standard potato production practices.

In conclusion, this study has demonstrated that the novel rap 119-2 EB resistance identified in laboratory studies is highly effective under field conditions. In addition, that resistance was

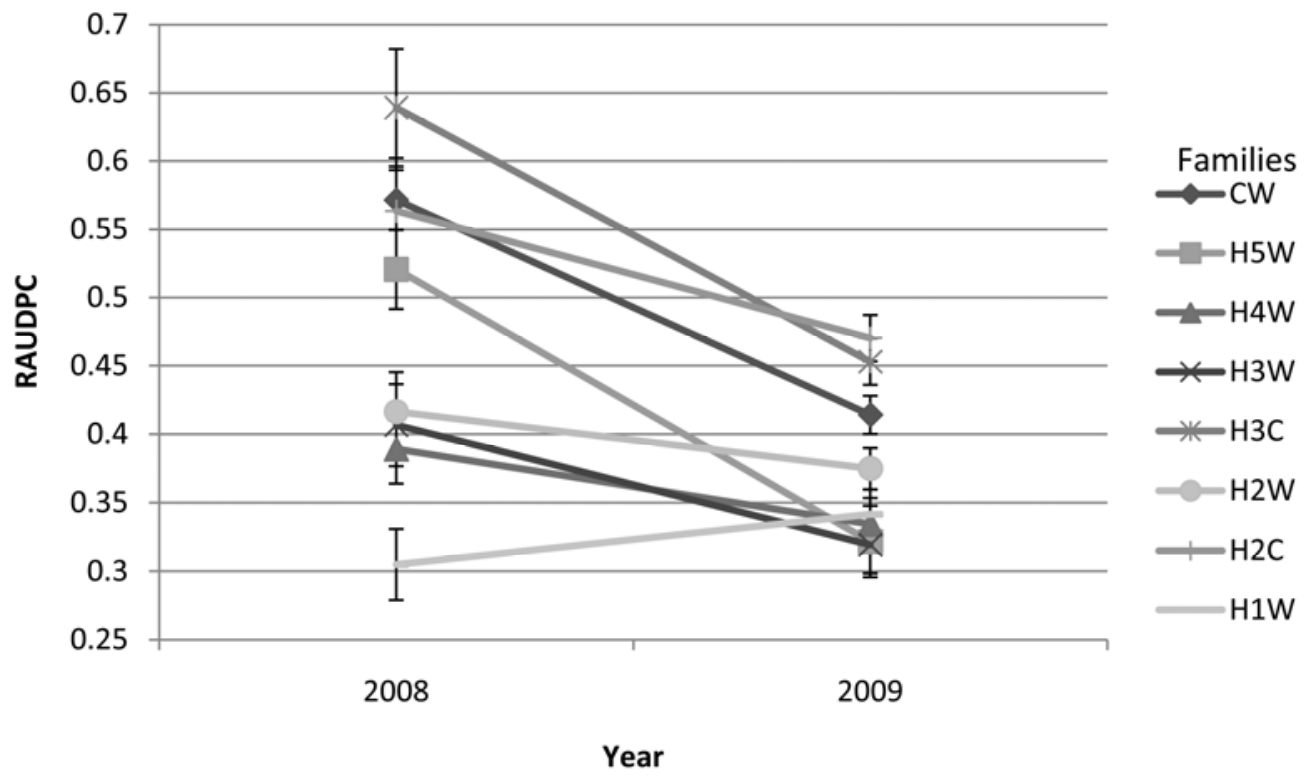

Fig. 4. Interaction plots of family relative area under the disease progress curve (RAUDPC) means between 2008 and 2009. High mean values indicate low early blight resistance.

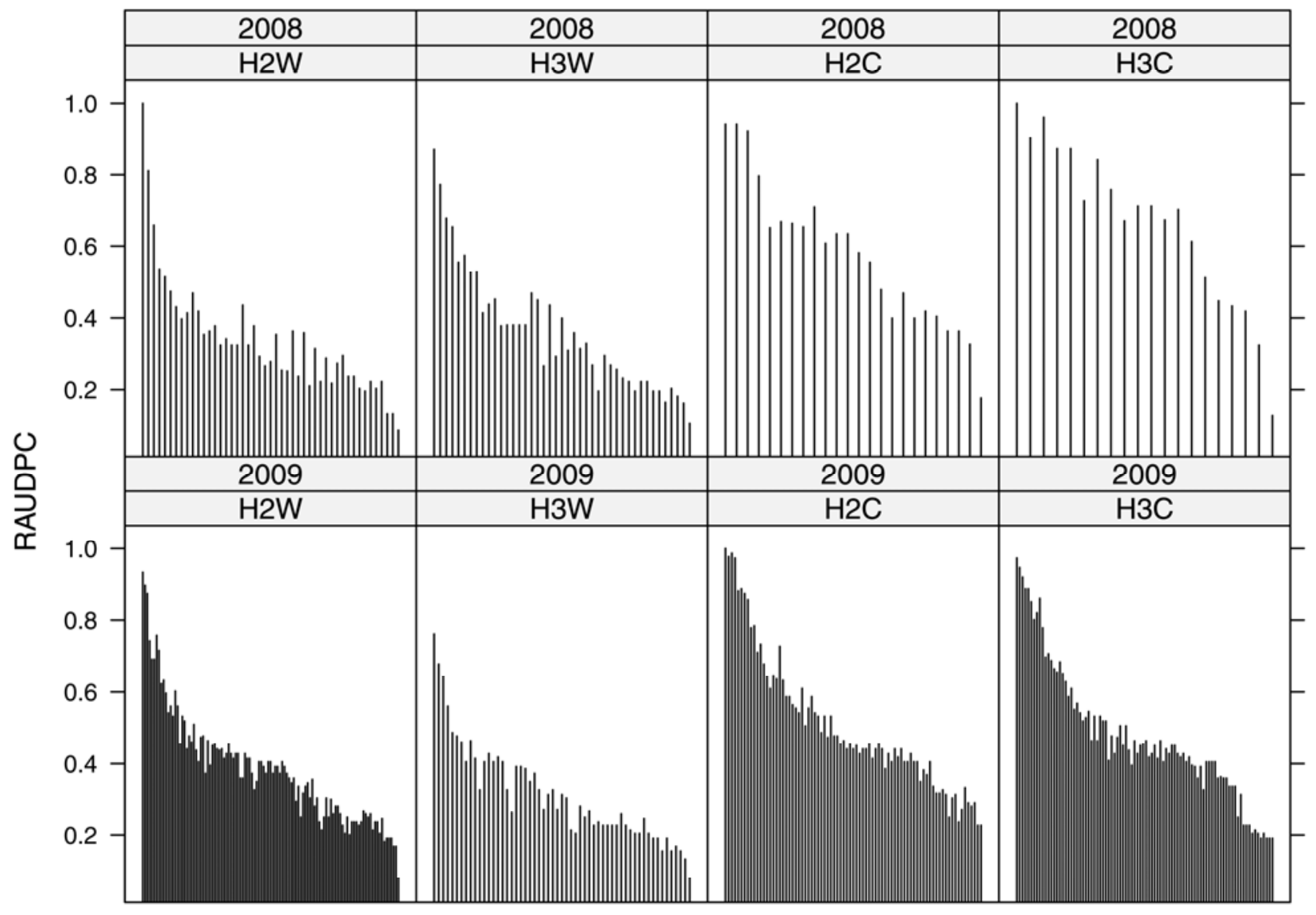

Individuals

Fig. 5. Frequency plots showing relative area under the disease progress curve (RAUDPC) score distributions of individual progeny in four selected haploid-wild hybrid species families (H2C, H3C, H2W, and H3W) in 2008 (top) and 2009 (bottom). Hybrids H2 and H3 were backcrossed to resistant wild Solanum raphanifolium (rap 119-2) to create families $\mathrm{H} 2 \mathrm{~W}$ and $\mathrm{H} 3 \mathrm{~W}$ and backcrossed to susceptible cultivated US-W4 to create families $\mathrm{H} 2 \mathrm{C}$ and $\mathrm{H} 3 \mathrm{C}$. 


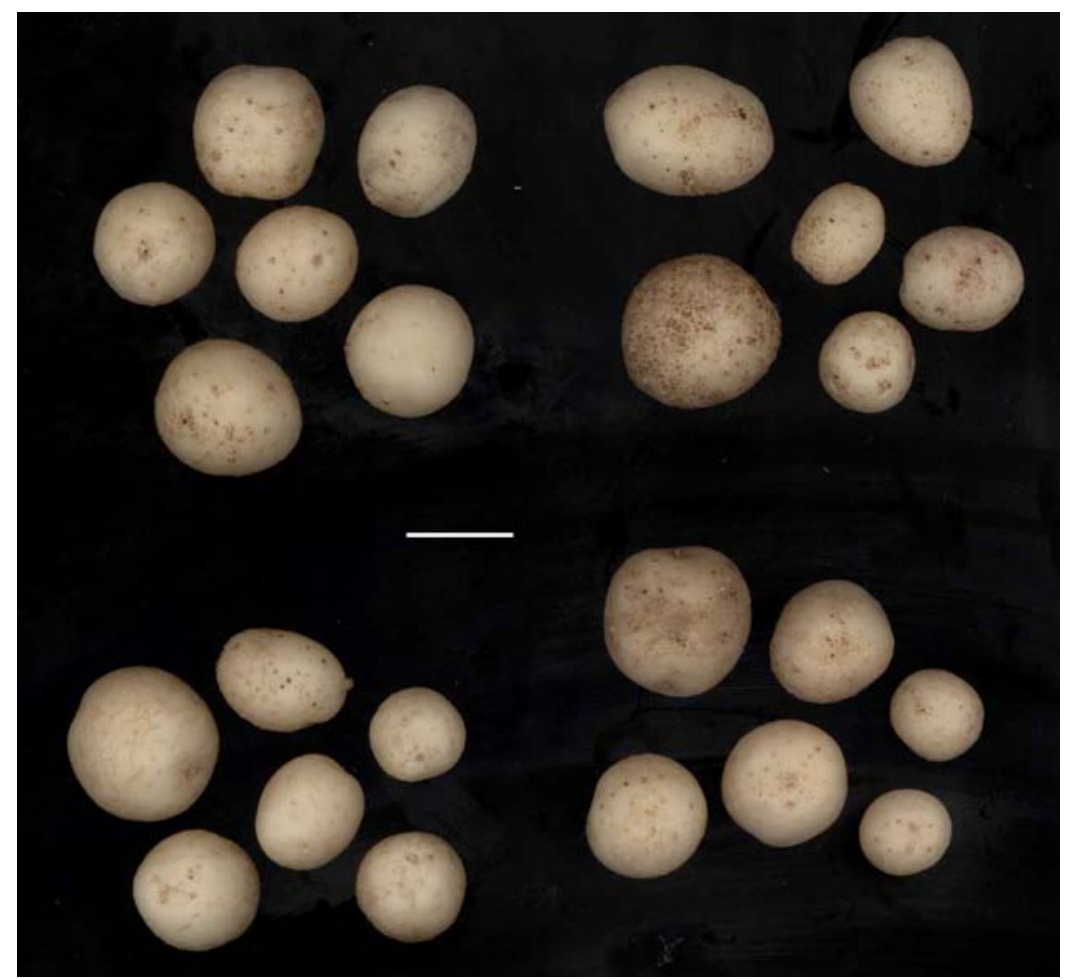

Fig. 6. Representative tubers of four clones of US-W4 $\times$ rap 119-2 hybrids from a subsequent 2010 early blight resistance field study. Bar $=1 \mathrm{~cm}$.

TABLE 3. Effect of male parents rap 119-2 and US-W4 (male), female parents $\mathrm{H} 2$ and $\mathrm{H} 3$ (female), and their interaction in 2008, 2009, and combined across years based on relative area under the disease progress curve family means

\begin{tabular}{lrcc}
\hline Year, source & DF & $F$ value & $P>F$ \\
\hline 2008 & & & \\
Male & 1 & 61.76 & $<0.0001$ \\
Female & 1 & 2.72 & 0.1017 \\
Male $\times$ female & 1 & 1.03 & 0.3115 \\
Error & 129 & $\ldots$ & $\ldots$ \\
2009 & & & \\
Male & 1 & 55.17 & $<0.0001$ \\
Female & 1 & 7.06 & 0.0083 \\
Male $\times$ female & 1 & 1.03 & 0.3106 \\
Error & 334 & $\ldots$ & $\ldots$ \\
Combined years & & & \\
Male & 1 & 119.01 & $<0.0001$ \\
Female & 1 & 0.01 & 0.9195 \\
Male $\times$ female & 1 & 1.97 & 0.1613 \\
Year & 1 & 11.03 & 0.001 \\
Year $\times$ male & 1 & 11.35 & 0.0008 \\
Year $\times$ female & 1 & 7.82 & 0.0054 \\
Year $\times$ male $\times$ female & 1 & 0.13 & 0.7141 \\
Error & 464 & $\ldots$ & $\ldots$ \\
\hline
\end{tabular}

transferred to offspring derived from crosses to the cultivated potato. Interspecific hybridization between $S$. tuberosum and $S$. raphanifolium is an effective strategy for potato breeders interested in developing adapted clones with high levels of EB resistance. Very few sources of resistance to A. solani have been documented in cultivated potato; therefore, it is vital to introgress new resistance sources into potato germplasm.

All evaluations of EB resistance in the $S$. raphanifoliumderived germplasm in this study have been carried out using $A$. solani isolates from Wisconsin, where virulence among isolates was similar. Consequently, further research is needed to assess resistance in different regions, where potato clones may be exposed to different isolates of A. solani. According to Weir et al. (21), genetic variation exists within A. solani across geographic regions, and isolates may vary in infection characteristics. A project is currently underway to evaluate EB resistance in US-W4 $\times$ rap 119-2 in northeast China.

It also would be interesting to further explore desired agronomic tuber traits such as formation, size, texture, and yield in the haploid-wild species hybrids that exhibited increased rates of EB resistance. Hybrids between US-W4 and wild Solanum spp. possess exceptional agronomical characteristics, such as small vines, short stolons, and large tubers (12). Two haploid-wild species hybrids (1-72-5 and 1-70-47) were selected in this study based on EB resistance, early maturity, and acceptable tuber production. Interestingly, 1-72-5 was created by backcrossing hybrid H2 to US-W4, while 1-70-47 was created by backcrossing hybrid H1 to rap 119-2. These clones have been included in field EB trials, where they continue to exhibit high levels of resistance and good adaptation to field conditions.

\section{ACKNOWLEDGMENTS}

Solanum raphanifolium germplasm was supplied by the NRSP-6 Potato Genebank. We thank V. James (University of Wisconsin-Madison) for technical expertise in the early blight evaluation procedure, and C. Ane and N. Keuler (University of Wisconsin-Madison) for statistical advice.

\section{LITERATURE CITED}

1. Agrios, G. N. 2005. Plant Pathology, 5 ed. Elsevier, London.

2. Anonymous. 2006. Procedures for standard evaluation trials of advanced potato clones. In: An International Cooperators' Guide. International Potato Center, Lima, Peru.

3. Bambawale, O. M., and Bedi, P. S. 1982. Epidemiology of early blight of potato in the Punjab. Indian Phytopathol. 35:574-582.

4. Campbell, C. L., and Madden, L. V. 1990. Introduction to Plant Disease Epidemiology. John Wiley \& Sons, New York.

5. Chaerani, R., and Voorrips, R. E. 2006 Tomato early blight (Alternaria solani): The pathogen, genetics, and breeding for resistance. J. Gen. Plant Pathol. 72:335-347.

6. Christ, B. J. 1991. Effect of disease assessment method on ranking potato cultivars for resistance to early blight. Plant Dis. 75:353-356.

7. Christ, B. J., and Haynes, K. G. 2001. Inheritance of resistance to early blight disease in a diploid potato population. Plant Breed. 120:169-172. 
8. Dita Rodriguez, M. A., Brommonschenkel, S. H., Matsuoka, K., and Mizubuti, E. S. G. 2006. Components of resistance to early blight in four potato cultivars: Effect of leaf position. Phytopathology 154:230-235.

9. Douglas, D. R., and Pavek, J. J. 1972. Screening potatoes for field resistance to early blight. Am. Potato J. 49:1-9.

10. Hijmans, R. J., Spooner, D. M., Salas, A. R., Guarino, L., and de la Cruz, J. 2002. Atlas of Wild Potatoes. International Plant Genetic Resources Institute, Rome.

11. Horsfall, J. G., and Barratt, R. W. 1945. An improved grading system for measuring plant diseases. (Abstr.) Phytopathology 35:655.

12. Jansky, S. H. 2011. Parental effects on the performance of cultivated $\times$ wild species hybrids in potato. Euphytica 178:273-281.

13. Jansky, S. H., Simon, R., and Spooner, D. M. 2008. A test of taxonomic predictivity: Resistance to early blight in wild relatives of cultivated potato. Phytopathology 98:680-687.

14. Pelletier, J. R. 1988. Computer simulation of cultivar resistance and fungicide effects on epidemics of potato early blight. Ph.D. thesis, Plant Pathology, Cornell University, Ithaca, NY.
15. Peloquin, S., and Hougas, R. W. 1960. Genetic variation among haploids of the common potato. Am. Potato J. 37:289-297.

16. Pscheidt, J. W. 1985. Epidemiology and control of potato early blight, caused by Alternaria solani. Ph. D. thesis, Plant Pathology, University of Wisconsin-Madison, Madison.

17. Rands, R. D. 1917. Early blight of potato and related plants. Pages 1-48. Wisconsin Agricultural Experimental Station Research.

18. Tek, A. L., Stevenson, W. R., Helgeson, J. P., and Jiang, J. 2004. Transfer of tuber soft rot and early blight resistances from Solanum brevidens into cultivated potato. Theor. Appl. Genet. 109:249-254.

19. van der Waals, J. E., Korsten, L., and Aveling, T. A. S. 2001. A review of early blight of potatoes. Afr. Plant Prot. 7:91-102.

20. Weber, B. N. 2009. Breeding for early blight resistance in potato using wild species Solanum raphanifolium, MS thesis, Horticulture, University of Wisconsin-Madison, Madison.

21. Weir, T. L., Huff, D. R., Christ, B. J., and Romaine, C. P. 1998. RAPDPCR analysis of genetic variation among isolates of Alternaria solani and Alternaria alternata from potato and tomato. Mycologia 90:813-821. 